\title{
Negotiating the Rental Rate for Optometry Tenants
}

\author{
By: Jeff Grandfield and Dale Willerton - The Lease Coach
}

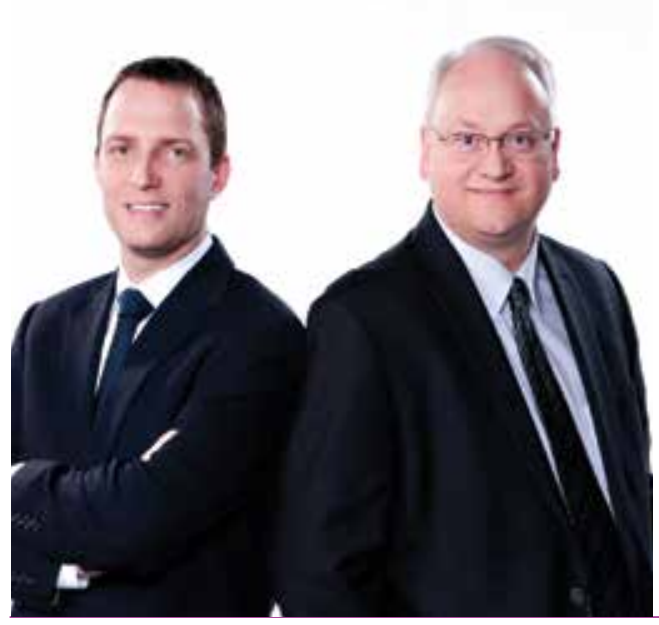

Dale Willerton is the founder of The Lease Coach and Jeff Grandfield recently joined him as partner. Dale and Jeff are commercial lease consultants who work exclusively for tenants, and are also professional speakers and co-authors of Negotiating Commercial Leases and Renewals For Dummies. Got a leasing question? Need help with your new lease or renewal? Call 1-800-738-9202, email DaleWillerton@TheLeaseCoach.com,or visit www.TheLeaseCoach.com. For a copy of our free CD, Leasing Dos \& Don'ts for Commercial Tenants, please email your request to DaleWillerton@TheLeaseCoach.com.

- very optometry tenant wants to pay the least amount of base rent possible. Every landlord Wants to get more rent. In negotiating your rent (either initially or when negotiating your lease renewal), it's important to realize that not all tenants pay the same rent per square foot that amount is negotiable based on many factors. It's equally important to understand that the landlord's asking rental rate is what they need to satisfy their financial commitments or what they hope to achieve in the marketplace and not necessarily what you can afford to pay in rent.

It should come as no surprise that rent is one of your major business expenses. Your rental rate is also a major factor if and when you sell your clinic. If a prospective buyer believes that your rent is too high, you may be unable to sell as the buyer is essentially scared off by the overhead.

Never underestimate the importance of the right rental price. Rent can make or break your clinic. If you're struggling to pay your rental rate, there are two possibilities: either your rent is too high or your patient count is too low.

If your landlord is smart, he doesn't just pull a rental figure from the air. A typical commercial developer sets rental rates based on a simple formula whereby the rental revenue from the tenants covers the mortgage and provides the landlord with a 7 - 15\% percent capitalization rate (or return on investment).

Mathematically, this is an easy calculation for the landlord - it involves two numbers or factors: the face rate versus the net effective rental rate. The face rate is the dollar amount you pay and the amount that appears on the lease agreement. The net effective rental rate is the amount left for the landlord after deductions for real estate commission, inducements and incentive packages, the landlord's work done to the commercial space, and so on. With a $\$ 24.00$ per square foot rental face rate, the net effective rent the landlord is left with can easily be reduced to $\$ 17.00$ per square foot after these deductions. 
While knowing what other businesses in the same building you lease space in is a good idea, expecting their rent per square foot to be the same as yours isn't always realistic. There are legitimate reasons why various tenants pay differing rental rates in the same property:

Size: With commercial rent charged by the square foot, tenants leasing larger areas may pay less rent per square foot than you. Conversely, tenants leasing a smaller unit may be paying a premium for the smaller space.

Term: The number of years the tenant has agreed to lease can also be a factor. A longer lease term doesn't necessarily mean a lower rental rate; it will depend on the current economy and occupancy of the property, at the time the lease was signed.

Inducements: The dollar value of the inducement package impacts the tenant's rental rate. Although most landlords build some financial inducements into their asking rental rate, the two are connected.

Timing: The timing of when a business becomes a property tenant matters. In a newlydeveloped property, the first and last tenant in may pay different rates.

Most commercial leases are triple net leases; this means that all costs related to the property are passed through to the tenants. These operating costs (also known as Common Area Maintenance / CAM charges) and property tax charges are typically stated as a separate or additional rent, which the tenant must pay. In some cases, the operating costs are equivalent to or even more than a tenant's base rent.

The base or minimum rental rates stated per square foot probably don't include any charges the landlord wants for signage, storage, parking, utilities, and so on. Other costs indirectly related to the lease can be property taxes, business taxes, and insurance. It's extremely important to have absolute clarity on what rents and related costs you have to pay.

A general rent range figure is that tenants should budget to pay between $5-12$ percent of their gross sales in rent. The higher your patient volume, the more important every percent becomes to your bottom line.

One doctor came to us and wanted help with a new lease. He had found a jewel of a location; however the rental rates per square foot were so high that we had to talk him out of the location because he would have been paying more rent than our other medical/healthcare clients. It simply wasn't realistic for him to expect to be able to pay a higher rental rate.

Landlords anticipate that the cost of living or Consumer Price Index (CPI) may increase over time, and it usually does. This is called inflation by its simplest definition. Therefore, the landlord wants to build steps, or annual increases, into a tenant's five or 10-year lease term. This may be stated as a rent per square foot, such as $\$ 25.00$ per square foot the first year with a $\$ 1.00$ per square foot increase each year thereafter. Many lease agreements state that the annual rent increase may be calculated as a percentile factor, such as 3, 4, or 5 percent. Fight like crazy on these annual base rent CPI and percentage increases. Every percentage point counts. In some parts of the country, landlords are satisfied to receive a flat rent for a full 5-year lease term. It's all negotiable.

Considering the average optometrist tenant stays in the same location for at least ten years, it's easy to calculate the total rent that you may pay to the landlord over that time period. This is often more than you've paid for a house! For this reason, you need to develop a grave respect for rent. On a monthly basis, it may not seem like such a big expense, but most optometrist tenants aren't leasing space on a monthly basis, but instead for a much longer term. The economy can crash and rebound in one entire lease term ... what you need is a long-term vision. 
While you are negotiating or renegotiating your rental rate, don't forget to include your operating costs as your secondary rent. Although most commercial real estate professionals may tell you that operating costs are not negotiable, there are aspects of these that can be changed to the tenant's favor. The landlord wants to make sure that the tenants pay for all the operating costs for the property. There's nothing unusual about that. But when we analyze operating costs for groups of tenants in a building, we frequently find that the tenants are subsidizing capital improvements that the landlord is using to increase the building's value.

When it comes to operating costs, look at what you're paying for. The majority of commercial and office lease agreements may stipulate the specific components of the operating costs that tenants need to pay for. Typical examples of valid operating costs include general maintenance, painting, lawn cutting, snow removal, and property insurance. Almost every lease agreement has an operating cost clause which typically defines these common area maintenance charges in either a short- or long-form manner. From a tenant's perspective, a longer description is better as it creates more certainty.

In one property we noticed that the property manager's salary was included in the tenant's operating costs. The landlord, however, refused to reveal the amount of that salary. We forced their hand and discovered that the property manager's salary was ridiculously high. It wasn't the category or the fact of the salary itself was inappropriate - just the amount.

Operating cost discrepancies come in two flavors: honest mistakes or dishonest calculations. In a building where the property is fully or close to fully occupied, the landlord may have less reason to try to profit from operating costs but may still try to enhance the property using the tenant's money. However, when a property has several vacancies, the landlord may want to avoid paying his proportionate share of operating costs for the vacant units. Therefore, the landlord may include language into the lease agreement stating that all of the operating costs will be passed on to the few tenants occupying the building. In some situations, tenants can be left carrying a very heavy burden if the property is not fully leased.

Communication with the landlord (both verbally and in writing) about any operating cost concerns you may have is imperative. And don't wait too long because the lease may stipulate a statute of limitations on adjustments. Sometimes the problem originates with the property manager, but sometimes it comes from the landlord or owner taking advantage of the tenants. If you catch your landlord with his hand in the cookie jar, don't be surprised if he's not cooperative or communicative.

For a copy of our free CD, Leasing Do's \& Don'ts for Commercial Tenants, please e-mail your request to DaleWillerton@TheLeaseCoach.com.

Dale Willerton and Jeff Grandfield - The Lease Coach are Commercial Lease Consultants who work exclusively for tenants. Dale and Jeff are professional speakers and co-authors of Negotiating Commercial Leases \& Renewals For Dummies (Wiley, 2013). Got a leasing question? Need help with your new lease or renewal? Call 1-800-738-9202, e-mail DaleWillerton@TheLeaseCoach.com or visitwww.TheLeaseCoach.com.

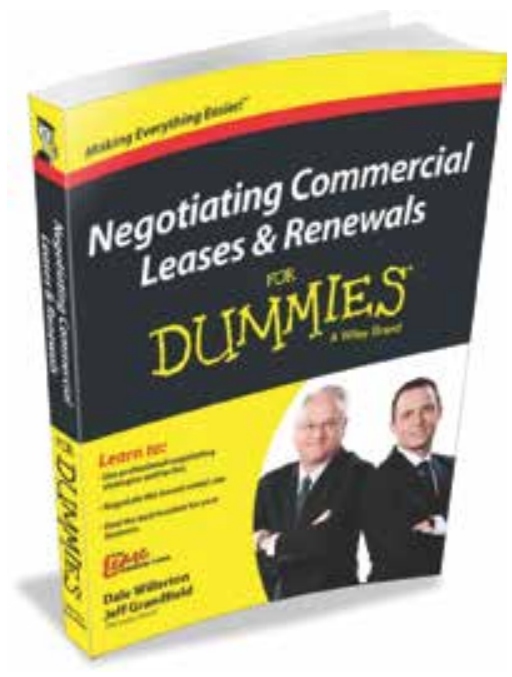

